Archived version from NCDOCKS Institutional Repository http://libres.uncg.edu/ir/asu/

\title{
Appalachỉan
}

B O O N E, N O R T H C A R O L I N A

\section{An Exploratory Study Of How Destination Marketing Organizations Pursue The Sports Tourism Market}

\author{
By: Richard W. Pouder, J. Dana Clark, and George G. Fenich
}

\begin{abstract}
In recent years, destination marketing organizations (DMOs) have taken advantage of the opportunities that sports tourism offers their communities. Although researchers acknowledge the important role played by DMOs in pursuing the sports tourism market, little is known about how they actually do so. This study is an exploratory attempt to identify specifically what actions DMOs have taken to seize these emerging opportunities. Using a fivestep analytic approach in interviews with DMO officials, four groups of dominant themes that DMOs considered in their pursuit of the sports market were identified. Each of these themes is discussed and their implications for practice and future research are considered.
\end{abstract}

Pouder, R. W., et al. (2018). "An exploratory study of how destination marketing organizations pursue the sports tourism market." Journal of Destination Marketing \& Management 9: 184-193. https://doi.org/10.1016/ j.jdmm.2018.01.005. Publisher version of record available at: https://www.sciencedirect.com/science/article/pii/ S2212571X17301476 


\title{
An exploratory study of how destination marketing organizations pursue the sports tourism market ${ }^{\text {ts }}$
}

\author{
Richard W. Pouder ${ }^{\mathrm{b}}$, J. Dana Clark ${ }^{\mathrm{a}}$, George G. Fenich, ${ }^{\mathrm{c},}$ \\ ${ }^{a}$ Hospitality and Tourism Management, Department of Management, John A. Walker College of Business, Appalachian State University, Boone, NC 28608, USA \\ ${ }^{\mathrm{b}}$ Appalachian State University, 4057 Peacock Hall, Boone, NC28608, USA \\ ${ }^{\mathrm{C}}$ School of Hospitality Leadership, College of Business, East Carolina University, Greenville, NC 27858, USA
}

\section{A R T I C L E I N F O}

\section{Keywords:}

Destination Marketing Organization (DMO)

Sport tourism

Strategy

Interviews

Markets

\begin{abstract}
A B S T R A C T
In recent years, destination marketing organizations (DMOs) have taken advantage of the opportunities that sports tourism offers their communities. Although researchers acknowledge the important role played by DMOs in pursuing the sports tourism market, little is known about how they actually do so. This study is an exploratory attempt to identify specifically what actions DMOs have taken to seize these emerging opportunities. Using a five-step analytic approach in interviews with DMO officials, four groups of dominant themes that DMOs considered in their pursuit of the sports market were identified. Each of these themes is discussed and their implications for practice and future research are considered.
\end{abstract}

\section{Introduction}

Destination Marketing Organizations (DMOs) were initially formed over a century ago to maximize the economic impact of visitors to a specific area. DMOs are not-for-profit organizations that act as the principal entity of a given political division or subdivision that competes and draws visitors to the distinctive destinations within its purview (Destination Marketing Association International, 2016; Pike \& Page, 2008). DMOs are largely financed by hotel occupancy taxes. In the state of North Carolina, for example, these taxes range from 3\% to $8 \%$, which is collected over and above regular state taxes. It is therefore very much in the self-interest of DMOs to maximize hotel usage to increase their own budgets. Perceived by visitors, 'DMOs are like a key to the city. As an unbiased resource, they can serve as a broker or an official point of contact for convention, business, and leisure travelers. They assist planners with meeting preparation and encourage business travelers and visitors alike to visit local historic, cultural and recreational sites' (Destination Marketing Association International, 2016). Although DMOs may suggest or sponsor events, they do not create them; their role is to search for and book existing events.

DMOs began as the government-authorized organization that marketed their locations to groups dominated by meetings and conventions. Over time, however, DMOs have expanded their marketing activities to encompass a wide range of planned events that enhance visitors' experiences with the goal of supporting the long-term economic development of communities through increased visitor spending. Support is most notable in communities in need of intensive labor industries to fill a void created by economic devastation. For example, North Carolina has experienced almost the 'perfect storm' as the furniture, tobacco and textile industries, three major industrial 'backbones,' have all seen major decreases at the same time. Recent growth in DMO planned events has helped many North Carolina towns and cities avoid economic devastation by bringing in visitor money from outside the community.

Given the growing importance of planned events to communities, DMOs have faced the need to recognize those tourism segments offering activities that maximize hotel usage by inspiring business travelers and visitors to engage in public celebration, competition, fun, entertainment, business, or socializing (Getz, 2008). Over the years, a variety of new segments such as tour buses, corporate and association meetings, weddings, and yearly festivals and events have emerged. The choice of segment depends to a great extent on the pressure that lodging organizations put on DMOs to increase occupancy at times when they are not busy. Many destinations, for example, seek to fill the holes in lodging occupancy created during certain times of the week or season. Corporate and association destinations, for instance, fill rooms during the week but need help during the weekend. Tourist destinations may need little help from DMOs during peak tourist season, but will seek events that can fill rooms off-season. Another consideration in a DMO's choice of which segment to pursue concerns the nature of service

\footnotetext{
This research did not receive any specific grant from funding agencies in the public, commercial, or not-for-profit sectors

${ }^{*}$ Corresponding author.

E-mail address: fenichg@ecu.edu (G.G. Fenich).
} 
provided by lodging properties. Corporate and association conventions fill downtown convention hotels, with limited service properties on the edge of town left out when DMOs go after conventions. Like all lodging entities, limited service properties pay occupancy taxes that support DMOs.

Through many informal conversations with DMO leaders over the past two decades, two of the authors of this paper have come to learn that DMOs' choice of an event segment is situational and largely dependent on factors described above. Interestingly, however, when it came to choosing a segment, conversations often turned to sports as a fast-growing event segment pursued in most communities. DMOs indicated that sports brings in visitors that fill hotels in the off-tourist season. Moreover, sports groups often prefer limited service properties, which are typically less expensive, offer free parking, free breakfast and. often, free Wi-Fi. With locations on the edge of town, they are also generally closer to sports infrastructure. DMO leaders also pointed out that many communities had overbuilt convention centers, which resulted in more convention infrastructure than there are groups to use it. With excess supply, convention center business is harder to get and increasingly less profitable (as evidenced in the 'deals/incentives' that some communities have put together to book business). This, too, has contributed to DMOs' pursuit of the sports market as a way to fill in a lodging gap.

Some research supports the rise of sports tourism in the United States, noting that nearly every North American city and many smaller towns have dedicated agencies and personnel to bid on sports events (Alexandris \& Kaplanidou, 2014; Getz, 2008; Russo \& Zarick, 2010). For example, the DMO for Pittsburgh, Pennsylvania recently created a Sports Commission as a division of the DMO. In Greenville, North Carolina, the DMO has commissioned a study of the feasibility of attracting more sports groups and making recommendations regarding what, if any, facilities should be added. Especially important in the rise of sports tourism in the United States are smaller-scale events such as amateur sports, 'Masters Sports' and disabled sports (Higham, 1999; Kaplanidou \& Gibson, 2010).

Researchers report that hosting sporting events can benefit destinations by enhancing their image development and exposure (Getz \& Page, 2016; Hinch \& Higham, 2004; Shonk \& Chelladurai, 2008) and by generating opportunities for creating tourism-based revenue from those who are affiliated with the event or from outside spectators who travel to see the event (Getz, 2008; Gratton, Dobson, \& Shibli, 2000; Morgan, Pritchard, \& Pride, 2011). For example, Russo and Zarick (2010) found in their survey of spectators at Virginia youth travel soccer tournaments that $72 \%$ of respondents sometimes plan vacations around a youth soccer travel tournament, with the majority of respondents staying in local motels for at least two nights. Also noted is a trend toward DMOs focusing more attention on sports-dedicated marketing to fill lodging vacancies created when organizations substitute on-site conferences with virtual meetings (Pittman \& McLaughlin, 2012).

Many authors have addressed sport tourism from a non-American perspective in terms of economic impact, building of facilities, attendance at events etc. Studies, however, tend to be very broad. Nyikana, Tichaawa, and Swart (2014) and Knott and Hemmonsbey (2015) suggest that hosting a sport tourism event can also lead to enhanced city visibility and to an improved city image while other authors suggest that sport tourism events have been identified as providing an exciting opportunity to market cities (Bob \& Swart, 2010; Emery, 2002; Knott \& Hemmonsbey, 2015; Tichaawa \& Swart, 2010; Standeven \& De Knop, 1999). Sport tourism is transforming destinations to become desirable (Bob \& Swart, 2010; Cornelissen, Bob, \& Swart, 2011; Nyikana et al., 2014). An entire book (Morgan, Pritchard, \& Pride, 2011) covers the concepts of destination brands, albeit largely from a European perspective. Rein and Shields (2007) discussed branding sports in emerging, transition, negatively viewed, and newly industrialized nations. They also note that sports tourism is a relatively underutilized segment.

Other studies have discussed economic impact and visitation.
Bawaba (2010) suggests that there are both economic and social benefits to be gained from sports tourism while another suggests that sport tourism can lead to substantial increases in visitation and tourism revenue (Desai \& Vahed, 2010; Tichaawa \& Swart, 2010). Another study supported the previous two by discussing how sport and tourism have grown significantly to become important economic activities (Gaffney, 2010; Smith, 2014; Swart \& Bob, 2007; Tichaawa \& Swart, 2010).

Physical development has been the thrust of other studies of sport tourism. Swart and Bob (2007) discuss the use of sport tourism as a tool for urban development. Siyabulela (2016) discusses using sport tourism events as a catalyst for tourism development in the Eastern Cape Province, South Africa. Ciampicacigli and Maresca (2004) focus on the idea that sports tourism leads to the development of symbiotic products and services, while others provide evidence that the sport tourism segment has seen notable growth (Ciampicacigli \& Maresca, 2004; Swart \& Bob, 2007).

All of the articles cited above address sports tourism from a 'macro' perspective. Further, even those that touch upon DMOs do so from a non-American perspective. The authors of the extant research have worked and interfaced with DMO executives from around the world. They are aware that DMOs in Europe operate differently from those in the US. European DMOs focus on creating identity and are not measured on how much business they bring to the destination. In the United States the thrust is just the opposite: to generate business by putting 'heads in beds.' These differences support the focus of the extant study, which is to ascertain the activities and strategies that DMOs in the United States are incorporating, or are going to incorporate, to facilitate increasing business in the form of sports groups. This research is not about how many people come to watch sporting events.

The foregoing discussion suggests that as the sports tourism market has emerged, DMOs have begun to take advantage of the opportunity afforded by its growing importance as a tourist destination. Whereas some research has acknowledged the role of DMOs in promoting sports tourism, little is known about the specific activities that DMOs engage in to do so. To address this gap in the literature, this study is an exploratory effort to identify specifically what actions DMOs have taken to seize the emerging opportunities in sport tourism. It begins by describing the methods used to conduct the study, followed by a discussion of the findings. The implications of the findings are then discussed along with the study's limitations and directions for future research. This study contributes to the body of knowledge by taking a first step in identifying key elements that determine how DMOs have pursued the sports market and facilitates opportunities for further research in the area.

\section{Methodology}

As noted, the goal of this study is to understand how DMOs have pursued the sports market. Because a review of the literature revealed no prior research that related closely to this topic, we have taken an exploratory approach that uses a qualitative research design. Qualitative research attempts to communicate interpretative and evaluative knowledge and is especially appropriate for studying phenomena for which little is known (Creswell, 2013), as is the case in our research. The phenomena sought in the qualitative research paradigm is the reality constructed by the participants in the research process. In this study, the realities of participants drew from the perceptions of interviewees as communicated verbally to the authors.

The qualitative research design adopted for this study used in-depth, semi-structured interviews conducted with DMO leaders experienced in attracting sports events to their communities. Before doing so, however, it was necessary to meet with destination marketing leaders who had expertise in sports tourism. Meetings took place with nine individuals or small groups of destination marketing leaders who were also members of the Destination Marketing Association of North Carolina 


\section{INFRASTRUCTURAL CONSIDERATIONS}

\section{BUILDERS}

Created new infrastructure

- Indoor facility

- Aquatic center

- Athletic fields

- Remodel convention center

- Convert old tobacco warehouse into indoor sports facility
INFRASTRUCTURE-LIMITED

Do not create new infrastructure, but could add new sports events to existing facilities

- Use infrastructure as is without adding new sports events

- Extend use of extant infrastructure to add new sports events (e.g., lacrosse, rugby, and ultimate Frisbee could be played on soccer fields)
NON-SPORTS-TARGETED INFRASTRUCTURE

Use manmade infrastructure not created for sports or naturally occurring infrastructure for sports events

- Roads, parks, etc. used for races and cycling events

- Waterways for water sports

- Suitable terrain for climbing/hiking events

- Farmland for mud run races

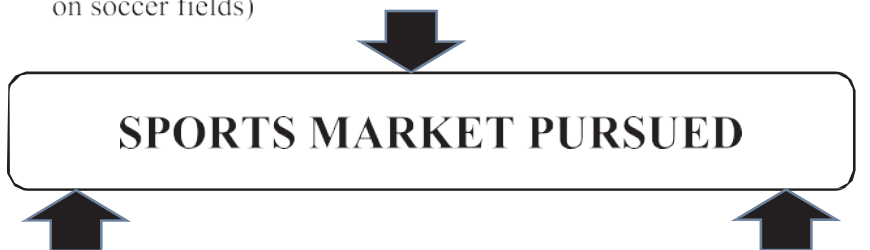

\section{SPORT CATEGORY}

\section{TRADITIONAL}

Sports that commonly comprise events in many communities

- Soccer, football, baseball, tennis softball, basketball, swimming

\section{EMERGING}

New sports for which a few communities are currently creating events

- Pickleball, cyclo-cross, theme races (noncompetitive fun runs, mud runs)

- A range of sports for 'senior' and 'master athlete' participants

\section{HOW DMO'S IDENTIFIED SPORTS}

MARKET OPPORTUNITIES

\author{
NICHE \\ 'Niche-type' established sports that \\ comprise events in a few communities \\ - Cornhole, wrestling, ice hockey, \\ iron-man, archery, senior sports, \\ master sports, table tennis, ultimate \\ Frisbee, karate, rodeo
}

Fig. 1. Three factors in the decision to pursue a sports market in ten North Carolina DMOs.
(DMANC). The following procedures suggested by Gillham (2005) were then applied. In order to understand fully the topic under investigation, these meetings proceeded as open-ended interviews in which interviewees gave their own answers to broadly structured questions that focused on the general question of identifying important trends in sports tourism and how DMOs have responded. After concluding these interviews, the research team felt confident that adequate information had been obtained to develop questions to serve as an interview protocol. As a first step, a list of twenty-two questions was prepared. Questions were then grouped by the topic that they most closely related to. After eliminating non-essential and redundant questions, and rewriting to ensure clarity, the final interview protocol consisted of eleven questions (see Appendix A).

Given the need to obtain information containing in-depth knowledge, all interviews for this study were conducted with DMO members who had extensive experience in sports marketing in their respective communities. In all cases, these were individuals who led their organization and/or headed the sales efforts. Scholars refer to interviews that involve talking to especially knowledgeable people in the area under investigation as 'elite interviews' (Bogner \& Menz, 2009; Gillham, 2005;). Following the recommendations of scholars, the authors adopted an approach in which protocol questions were used consistently in the interviews, but the interviews were loosely structured in order to give respondents greater flexibility in how they answered questions. Using this approach allowed for unexpected and valuable responses that drew from the interviewee's 'more authoritative grasp of the subject' (Gillham, 2005, p. 54). Further, the expert interview is a frequently used instrument for collecting data in exploratory studies where it 'can serve to establish an initial orientation in a field that is either substantively new or poorly defined' (Bogner \& Menz, 2009, p. 46). Accordingly, elite interviews were conducted using the interview protocol with ten DMOs in North Carolina (see Appendix B).
To capture a representative range in size, DMOs with budgets that varied from just under $\$ 1,000,000$ to as high as $\$ 15,000,000$ were interviewed. The interviews were done in person, on site at the locations of the DMOs. The length of a typical interview was two hours. Extensive notes were taken for each question in the protocol.

Using the five-step analytic interview process outlined by McCracken (1988), the information in transcripts was initially analyzed by individual interview and understood individually. Each question was then considered from the perspective of all the interviews in order to identify common themes that emerged in the context of DMOs' pursuit of the sports market. Consistent with McCracken (1988, p. 45), at this stage of the analysis it was found that 'a field of patterns and themes should be (was) rising into view.' The dominant patterns and themes arising from the observations fell within four groups as follows:

1. Decision to Pursue a Sports Market - Key factors that influenced DMOs' decisions to enter a particular sports market

2. Approaches Used to Enter a Sports Market - Once chosen, what approaches DMOs used to pursue a particular sports market

3. Trends - Emergent trends in the pursuit of sports markets by DMOs

4. Key Considerations - What communities identified as the most important considerations in pursuing a sports market.

Continuing with the five-step process, attention focused on the clusters of comments made by each DMO that fell within each of the four groups. As noted by McCracken (1988), at this stage, the researcher is now ready to discuss the general properties of the grouping being studied. Since the extant study is 'exploratory' and given a limited number of DMOs interviewed, the findings are 'synopsized' in a discussion format and analyzed visually rather than statistically. A key feature of the discussion format is that it incorporates direct quotations from expert sources as data that enriches the information content of 
individual interviews, creates access to new information, and initiates and gives direction to the research (Gillham, 2005).

\section{Findings}

Many interviewees suggested that their DMOs had changed over the years by becoming organizations increasingly focused on management rather than being strictly marketing organizations. As such, they were better able to, as one interviewee pointed out, 'spot holes' in their product offerings and, in many instances, worked actively with public and private entities to fill these 'holes.' The growing popularity and intrinsic advantages offered by the sports tourism market discussed above were recognized by DMO leaders as an effective way to fill gaps in their product offerings.

\subsection{Decision to pursue a particular sports market}

After making the decision to pursue the sports market, three key factors emerged that guided choices on which sport to pursue: infrastructural considerations, sport category, and how DMOs identify new sports market opportunities. The degree to which each factor influenced decisions varied considerably and in most DMOs' decisions involved a complex interplay of multiple factors. Fig. 1 provides details for each factor.

\subsubsection{Infrastructural considerations}

DMOs in all cases needed to consider the availability of infrastructure for a given sport. DMOs indicated that they can identify needs and potentials. Many DMOs have come up with formulas for monetary support depending on the expected economic impact of a potential group. Some groups need specific types of facilities, while others do not. DMOs are aware of building specs needed for groups (ceiling height, court widths) and are often involved in design discussions for any new sports-related infrastructure. This all had to be approached delicately, however, for two reasons. First, while they could demonstrate the need for new infrastructure, the political answer could well be the use of the very occupancy taxes that support DMOs. Another consideration mentioned was the interplay between public use of the new facilities and the out-of-town use of new facilities.

Three possible scenarios regarding infrastructural considerations were noted. Some DMOs were in communities characterized as 'builders,' where new infrastructure was created to pursue a sports market. For example, one community built an aquatic center, a second constructed an indoor track facility, and several other communities acquired land to build new fields for soccer, baseball, softball, and other sports. In other cases, builders substantially modified facilities currently not used for sports events as, for example, when convention centers were modified for certain indoor events. Builders seek competitive advantage by targeting specific sports markets and then providing the necessary infrastructure. In essence, they 'buy' their way into being competitive for a desired sports segment.

Other communities had existing infrastructure for certain sports, but had no interest in building new facilities. In such 'infrastructure-limited' cases, some DMOs remained tied to the same sports market; their ability to expand sports infrastructure was limited by politics or other community realities. As one DMO marketing representative pointed out, 'Our elected city officials have seen no need to bring in new types of sports events and are unlikely to do so in the future.' However, other 'infrastructure-limited' DMOs were able to pursue new sports markets without building new infrastructure by using existing facilities to serve multiple sports. For instance, DMOs often recognized that bringing in new sports such as lacrosse and rugby could be easily accommodated on fields currently used for sports such as soccer and football. The guiding principle in these DMOs was maximizing the potential value of what they have in place. Another source of available infrastructure to communities that faced limitations in building new infrastructure was to use privately owned facilities. One DMO sponsored track and field competitions at a site built and owned by a former world-class runner. Another sponsored 'mud runs' on local farmland, commenting that this event 'brought in hundreds of runners at minimal cost to the city.'

The third way in which DMOs considered infrastructure involved the use of 'non-sports-targeted infrastructure,' which was either infrastructure available in the natural environment that communities did not create or manmade infrastructure that was not created for sports events, but could be used for sports events. For example, some communities used rivers and lakes for water sports such as rowing, while other communities took advantage of mountainous terrain for climbing events. Manmade infrastructure such as roads and parks created opportunities for races and cycling competition in several communities. The head of one DMO said, 'one of our most successful sports events is a 'race to the top' contest on a small, but steep mountainside.'

\subsubsection{Sport category}

Keeping in mind the role of infrastructure, DMOs also considered what type of sports markets existed. The extant study identified three sport categories selected by DMOs. Some DMOs selected only one category, but most were more likely to select two or three categories. The first category, 'traditional sports,' are sports that are widely played and have traditionally comprised events across communities. Examples include baseball, basketball, softball, football, tennis, swimming/diving, track and field, and cycling. In contrast, it was found that DMOs in many communities are promoting 'niche sports' as a second category. This group was comprised of established sports that were not commonly pursued across communities. Examples included corn-hole, Ironman triathlon, wrestling, and archery. The third category of sports market pursued by DMOs consisted of new sports that were gaining popularity: a category which is labeled as 'emerging.' Communities pursuing newly emergent sports reported a desire to be 'first to market' by hosting competitive events in Quidditch, pickleball, and cyclo-cross. A DMO leader in a small city reported that, 'by being one of the first communities in the state to hold pickleball tournaments, we have been able to book new groups from throughout the region at an increasing rate.'

\subsubsection{How DMOs identify new sports market opportunities}

Information on opportunities for entering new sports markets came from several sources which the research team categorized as 'conventional sources' and 'unconventional sources.' All but one DMO said that they were members of various DMO-related trade organizations that served as a conventional conduit for information on new sports market opportunities. This information was obtained through formal presentations and informal interaction with other participants in meetings, as well as from organizations' publications. Another information source mentioned by one DMO was the internet. In this case, searches were conducted in Google and social media using 'unique sports' as a search term.

A number of DMOs, however, emphasized the importance of organizations and individuals outside of their conventional trade-based sphere of interactions. An important unconventional source to several DMOs was membership in local organizations such as the Chamber of Commerce and the Rotary Club. Also important were local 'grass-roots' networks with members of the local community who had ties to sports. For example, the owner of a local bicycle shop had provided evidence that supported the idea of the community sponsoring cycling events. Another DMO reported that, 'we regularly correspond with local sports clubs to access information on new sports market opportunities. Three new events were brought to our city last year by doing this'

\subsection{Approaches used to enter a sports market}

In the study at hand, two general approaches used by DMOs to enter a chosen sports market were identified: leveraging financial and physical assets, and leveraging skills and knowledge. DMOs usually used both 
FINANCIAL INCENTIVES

Secure additional funds for sports events that potentially offered a high return on investment for the community, most often

for high prestige events and events that

would come during off-peak times of the year

\section{FACILITY INCENTIVES}

Host community offers their existing

facilities for free or at a reduced rate.

\section{ENTRY APPROACH USED IN A CHOSEN SPORTS MARKET}

\section{LEVERAGING SKILLS AND KNOWLEDGE}

\author{
SALES AND MARKETING TACTICS \\ - Advertising in publications \\ - Participation in sports trade shows \\ - Providing superior service to sports groups
}

\author{
NETWORKING TACTICS \\ DMOs network with citizens or groups in \\ the local community with influential ties to \\ sports groups to help book events
}

approaches and, for each approach, often used several tactics to bring in sports events. Fig. 2 summarizes approaches DMOs used to enter sports markets.

\subsubsection{Leveraging financial and physical assets}

Specific tactics that DMOs used in this approach were to entice a sports group to pick a particular destination by providing 'financial incentives' and/or 'facility incentives.' DMOs offered incentives when a sports event potentially had a high return on investment for the community. Although financial incentives were subject to budgetary constraints, some DMOs were able to access additional funds to offer financial incentives for a high prestige event or for an event that would come at a very slow time of year for the community. Several DMOs, for example, subsidized part of guests' motel expenses beyond normal rebates for high prestige soccer events that occurred annually. In DMOs using facility incentives, the host community offered their existing facilities for free or at a reduced rate. As one DMO leader stated, 'we offered a no-fee policy that attempted to bring in a national Ironman triathlon competition. It should be noted that one DMO vehemently opposed any sort of financial incentives for sport groups or of 'buying any sort of group business' in general. In its opinion, this had gone too far and that the benefits of bookings using rewards rarely justified the eventual economic results.

\subsubsection{Leveraging skills and knowledge}

DMO tactics used to enter a chosen sports market also included those that relied more on the skills and knowledge of those within and outside of the DMO than on finance and infrastructure. Skills and knowledge originating within the DMO were classified as 'sales and marketing,' whereas skills and knowledge coming from outside the DMO were classified as 'networking.'

One widely used tactic in sales and marketing was advertising in publications. Examples included targeting a specific sport in publications dedicated to that sport, as well as advertising in less focused publications likely to be read by sports groups. One DMO reported that, 'usually three of four times a year we hit all the magazines that target cycling as a main article topic.' Another widely used tactic was to participate in one or more sports trade shows where DMOs would freely interact one-on-one or set up a booth to attract potential sports buyers. Some DMOs said that they do considerable work in advance to identify potential clients, adding that they need to build a knowledge base customized for each sport and client's circumstances. DMOs using sports trade shows as a tactic emphasized the importance of potential client follow-up, with one DMO saying that it, 'sends personalized letters and brochures several times after it meets with a new opportunity at the annual trade show.' A third conventional tactic used by DMOs was to market their track record in providing superior service to sports groups. Examples mentioned included dedicated personnel for free transportation services, gift packets and shopping coupons for event participants and their families, convenient access and parking for events, and special social events. A person who handled sports marketing for a DMO in a large city said that, 'we hand out brochures with testimonials from satisfied groups on the excellent services that we have provided to various sports groups.' DMOs felt that an established record of excellent service reduced the risk of sports buyers who were booking a destination for the first time; it also reduced the risk for these buyers when rebooking a host destination.

Networking tactics follow from the unconventional sources of information on new sports market opportunities discussed above. In this case, DMOs networked with citizens or groups in the local community to help them book an event as a result of their influential ties to sports groups. For example, one community used representatives from local softball leagues to contact national representatives of softball organizations for the purpose of bringing in regional and national softball tournaments. Unconventional sources seemed to work particularly well in DMOs that participated minimally in marketing through trade shows or media advertising.

\subsection{Trends}

DMO interviewees identified emergent trends in their pursuit of sports markets that fell under four predominant themes: breadth of $f a-$ cility use, competition and cooperation, temporal demand patterns for sports events, and new sports. Fig. 3 shows these trends.

\subsubsection{Breadth of facility use}

As discussed earlier, the availability of infrastructure was important in a DMO's decision to pursue a sports market. Developing new facilities was important for some DMOs. All DMOs, however, emphasized the importance of getting the most out of existing facilities. Instead of seeking new infrastructure, DMOs would capitalize first on the multipurpose potential of what they currently had. This enabled DMOs to bring in new sports with minimal investment. In the words of one interviewee, 'multi-purposing is being resourceful and allows us to boost occupancy.'

\subsubsection{Competition and cooperation}

A majority of DMOs brought up issues regarding competition for sports events. The pattern perceived by DMOs was that competition among communities has lessened over time, although a few DMOs 


\section{BREADTH OF FACILITY USE}

- Getting the most out of existing facilities

\section{COMPETITION}

\section{AND COOPERATION}

- Communities still compete, but trend is toward cooperation that promotes bringing events to the state and refers potential clients to communities with a reputation for excellence in certain sports - High level of cooperation with local colleges and universities
Fig. 3. Key emergent trends in sports markets identified by ten North Carolina DMOs.

\section{EMERGENT TRENDS \\ 3. TEMPORAL DEMAND PATTERNS FOR SPORTS EVENTS \\ - Maximum utilization of facilities sought on weekends to book readily available hotels - Attempt to extend season when certain \\ 4. NEW SPORTS \\ - Huge market growth opportunity for local, regional and national sports events - Build strong relationships quickly to book events} sports are played admitted that there was greater competition for certain groups, especially those that offered the greatest economic impact and came during the 'slow part of the year.' Most DMOS, however, remarked that the current trend was toward greater cooperation. All but one DMO participated in state-wide sports marketing groups to do cooperative marketing. The general consensus was that a primary goal of cooperative marketing was to bring more sports groups into North Carolina than into neighboring states. Communities still competed with each other for sports groups, in particular for the most common amateur sports such as soccer, softball, baseball, and football. However, in some cases, when communities can't handle more sports events than they currently have booked, they recommend other communities in the state that can. A DMO leader claimed that, 'if the occasion arises at a conference or trade show, we all try to help bring sports into the state, even if it's a sport the city doesn't offer.' Further, with each community often building a reputation of excellence for certain sports events not pursued by other communities, state-wide marketing groups would recommend that community to new sports groups. For example, a community known for its excellence in aquatic sports was routinely recommended as a destination by state-wide marketing groups. Another area where cooperation was critical to nearly all DMOs was partnerships with local colleges and universities. In no instances did communities compete with colleges and universities for sports groups. Rather, colleges and universities frequently provided their facilities for community sports events. In the words of one interviewee, these symbiotic relationships often helped colleges and universities 'market their unique brand.'

\subsubsection{Temporal demand patterns for sports events}

DMOs have had to deal with balancing supply and demand for sports events facilities on the basis of weeks and seasons. Most sports events took place on weekends. This worked out especially well in terms of available hotel bookings for communities with a Monday through Thursday corporate travel or convention base. The goal in all cases was to schedule events so as to maximally utilize facilities. Such events, however, were generally constrained by season, as many sports are played only at certain times of the year. A trend among DMOs in regard to seasonality was their ability to extend seasons for certain sports. For example, several interviewees remarked that soccer events are now booked for all seasons rather than for just during summer and fall. Many DMOs also reported that they have grown demand for sports events during 'off-peak' times of the year by pursuing new and emerging sports. For example, several communities have added pickleball and Quidditch to their events roster when more traditional sports are not played. One interviewee said that his city, 'has pickleball tournaments for senior citizens from across the state played on tennis courts during weekdays when the courts get low traffic.'

\subsubsection{New sports}

A recent trend that was mentioned by all interviewees was new and emerging sports as a huge market growth opportunity for local, regional, and national sports events. Perhaps best summarized by one DMO leader, 'we are truly amazed at the appearance of brand new sports and how quickly they have become popular.' A current practice noted by some DMOs was that they attempted to build strong relationships and bring in these sports quickly before those who were booking the events became more sophisticated in negotiating deals.

\subsection{Key Considerations}

Key considerations emerged as a descriptive and interpretive grouping that encompassed all three prior groupings. In other words, these represent what DMO decision makers considered most important in pursuing a sports market given the range of factors that influence decisions, the various approaches available, and emergent trends in the field. We observed that DMO interviewees focused attention on considering eight themes in pursuing the sports market: economic impact, restructuring the organization, relationship marketing, building a sports brand, exploiting local relationships, exploiting non-dedicated infrastructure, exploiting the potential breadth of facilities, exploiting non-traditional and emerging sports. Fig. 4 summarizes these eight themes.

\subsubsection{Economic impact}

All DMOs expressed the need to consider the economic impact to the community in deciding which sports groups to pursue. A challenge faced by all DMOs was how to allocate available funds among sports groups. The most commonly used metric in making underwriting decisions was an estimate of return on investment to the community. Sports events that might have greater potential impact were often less likely to be pursued because they required substantially higher underwriting dollars. In the extreme, some potentially attractive groups may cost so much to underwrite that it would make little economic sense for a community to pursue their business. One DMO head cautioned that communities should not get caught up in an 'arms race mentality' and pursue economically unattractive sports markets. In the minds of some interviewees, there will be even greater competition for certain sports events in the future. Because of this, they felt that sports groups will have greater bargaining power, which could lessen the economic impact of sports events to the community. Another important concern expressed was for communities to avoid overbuilding sports infrastructure so as not to carry excess capacity: a trend they associated with convention centers. One interviewee commented that, 'we got burned in building a huge convention center that has suffered from being underutilized.' 


\author{
1. ECONOMIC \\ IMPACT \\ - How to allocate funds \\ - Return on investment \\ to the community \\ - Competition increasing \\ for some sports events
}

\author{
2. RESTRUCTURING \\ THE ORGANIZATION \\ - How to change structure \\ to seize sports market \\ opportunities \\ - Use of volunteers
}

\author{
3. RELATIONSHIP \\ MARKETING \\ - Identifying important contacts \\ - Building and nurturing \\ relationships \\ - Ensuring continuity \\ with groups after events end
}

\author{
4. BUILDING A \\ SPORTS BRAND \\ - How to build a community \\ sports brand \\ - Move before other communities \\ - Tap into unique infrastructure \\ - Potential to build image on service
}
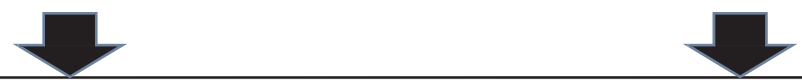

\section{KEY CONSIDERATIONS IN PURSUING A SPORTS MARKET}

\section{EXPLOITING LOCAL \\ RELATIONSHIPS \\ - Networking with local citizens having contacts in sports markets \\ - Use contacts to help \\ book events}

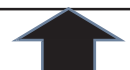

\author{
6. EXPLOITING \\ NON-DEDICATED \\ INFRASTRUCTURE \\ - Available infrastructure \\ readily usable without \\ need to build new facility
}

\author{
7. EXPLOITING THE \\ POTENTIAL BREADTH \\ OF FACILITIES \\ - How to seize advantages \\ of multi-purposing new or \\ existing facilities
}

\author{
8. EXPLOITING \\ NON-TRADITIONAL \\ AND EMERGING SPORTS \\ - Seek opportunities in new and \\ emerging sports \\ - How to schedule events for these \\ sports most efficiently
}

Fig. 4. Eight key factors considered by North Carolina DMOs in pursuing a sports market.

\subsubsection{Restructuring the organization}

DMOs reported the need to consider changes to their organizational structure as opportunities grew for communities to pursue the sports market. All DMOs selected individuals or formed teams that engaged in sports marketing. In the larger communities, these persons were dedicated entirely to the sports market and were often based in newly created divisions in the DMO or in 'sports commissions' comprised of members from government, universities, and community members with ties to particular sports events. In addition, some DMOs noted that it is important to consider bringing in volunteers from the community to assist in providing services at sports events: a form of support commonly provided for convention groups. For example, one DMO reported that it uses volunteers 'to host events, serve as timers in races and swimming competition, and put up fencing around facilities.' To determine the amount of free volunteer support, DMOs used a formula to estimate the economic impact on the booking group. Many DMOs indicated that they have formally assigned volunteer recruitment and training to a person on staff.

\subsubsection{Relationship marketing}

One of the most common statements made by DMOs regarding what was important to consider in pursuing the sports market was the need to spend time and effort establishing and nurturing relationships with sports groups. After identifying key contacts in sports groups, it is critical for DMOs, in the words of one interviewee, 'to show sincere interest and convey trustworthiness that builds a foundation for continuity in the relationship.' DMOs expressed their interest in sports groups by going to tournaments in other communities, attending sports conferences, and hosting important contacts on familiarization trips in the communities. Creating continuity in relationships involved making follow-up calls immediately after events and at select times in the future.

\subsubsection{Building a sports brand}

A majority of interviewees felt it was critical to consider how to build and maintain a sports brand such that their community was identified in the minds of some sports groups as the community when it came to a particular sport. To do so, some DMOs used such tactics as early building of specific infrastructure, early hosting of certain events, and/or press coverage of certain sports events that put their community 'on the map.' For example, one DMO acknowledged its community status as the 'locus of competitive cycling events in the state' by having the best racing facilities and unique track designs. Other interviewees indicated that they mentally branded themselves in the minds of sports planners as being good host communities in general for sports. One DMO reported that it was highly regarded among youth sports organizations by 'offering the best services for participants and their families.'

\subsubsection{Exploiting local relationships}

As noted earlier, networking approaches to exploiting relationships at the local level were found to influence decisions to enter a sports market. A surprising number of interviewees mentioned this point, including the influence of a local sports team or league and local citizens on regional and national sports boards to help book future tournaments. Even in smaller destinations, DMOs were able to identify such local relationships and parlay their influence into successful bookings.

\subsubsection{Exploiting non-dedicated infrastructure}

Also, as noted earlier, some DMOs have taken advantage of 'nondedicated infrastructure': that is, natural and man-made infrastructure that can readily be used for certain sports events without building a new facility. Most DMOs now consider pre-existing infrastructure such as roads for use in races and cycling events. Some DMOs, by virtue of their natural resource endowments, consider imaginative uses of farmland, waterways, and mountains in seeking new sports markets. As the head of one DMO put it, 'we are blessed with two major rivers that have attracted three different sports events at least once every year.'

\subsubsection{Exploiting the potential breadth of facilities}

Discussed above under important trends in more efficient utilization of facilities, it was found that all DMOs now consider the potential breadth of facilities in pursuing sports markets. A comment made by some interviewees was that the need to 'multipurpose' their facilities will increase as certain sports markets mature. Others noted that when considering new infrastructure for specific sports, they focus attention on facilities that can host multiple sports so not as to become 'locked-in' by narrowly designed facilities. In the words of one interviewee, 'we advised the city not to give much thought to developing a new facility that allowed for only competitive events in cycling.' 


\subsubsection{Exploiting non-traditional and emerging sports}

Also discussed above as an important trend, interviewees in all communities now consider the opportunities presented by new and emerging sports. Most of these sports could utilize existing facilities and often were considered attractive because they could be scheduled when more traditional sports events were not taking place. Consideration of opportunities to be resourceful and actually create new sports events was mentioned by several interviewees. For example, one community created 'bad sports' events for low-quality, young participants, noting that such events 'brought in big numbers of kids and their families and relatives who realized that this was a one-shot deal because these kids were not going to be serious athletes in the future.' Several communities sponsored competitive events for high quality amateur senior athletes.

\section{Discussion}

This study has shed light on how DMOs in North Carolina have pursued the sports tourism market. A number of findings were both interesting and surprising. Most striking was how quickly this market has grown, and with surprisingly no or minimal coverage of DMO involvement in the academic and practitioner literatures. It was only through informal discussion with DMO leaders that two of the authors of this paper became aware of DMO involvement in sports tourism. In pursuing this as a research topic, findings indeed indicated that DMOs were reconfiguring budgets and staffs to pursue this growing market. Yet in doing so, many DMO leaders envisioned an inevitable decline in the overall rate of growth in sports tourism. This suggests awareness of a tourism life cycle evolution in which the sports market, currently in a growth phase, will ultimately move into a 'consolidation stage ... where the rate of increase of visitors has declined, though total numbers are still increasing' (Cooper \& Jackson, 1989, p. 379). Under such conditions, one would anticipate more intense competition. Although interviewees acknowledged the existence and reality of competing with other DMOs for sports events, and that this will likely increase over time, many felt that they actually perceived less competition now than in previous years. While somewhat perplexing, there may be several reasons why this is the case. One possible explanation is that DMO leaders will continue to see attracting new or emerging sports to their communities a way of counteracting a slower rate of growth opportunities for traditional sports. DMO leaders have used impressively innovative, resourceful approaches to provide facilities for these sports. In line with manmade or natural attractions as a key element in the hospitality industry (Fenich, 2016), DMOs have taken advantage of the natural environment or built facilities that accommodate new or emerging sports.

Another factor that may act to dampen perceptions of increasing competition is recognition among DMOs of communities that have created a branded reputation of being 'the' place to go for a particular sport. As noted by Morgan et al. (2011), 'place reputation becomes the key to competitiveness' (p. 8). Interviewees seemed to acknowledge this to the extent that many communities would not vie for a sporting event when another community has built a well-recognized reputation for that event. Moreover, DMO leaders tended to work cooperatively rather than competitively by having their state-wide marketing groups promote destinations with a branded identity for a particular sport.

Munro and Richards (2011) report that DMOs increasingly rely on digital channels to advertise and to obtain information from blogs and social media for feedback on tourists' experiences. Interestingly, only one of the interviewees had discussed the importance of building internet searches and social media into their marketing activities. While all DMOs used digital channels, interviewees emphasized relationship marketing as the primary means for building and sustaining growth in sports tourism. Accordingly, DMO marketing staff rely on personal interaction to get to know the leaders/decision-makers for each sports group by going to trade-shows, making personal sales calls, and getting leads from people participating in the sports. It seems likely that DMOs' sports marketing efforts will continue to be relationship driven. What is unclear, however, is the degree to which revolutionary changes brought about by digital channels in customer relationships and access to information (Munro \& Richards, 2011) will influence how DMOs market their destinations for sports events.

The findings also highlight the importance of what Morgan et al. (2011) describe as the 'soft,' less tangible factors that can differentiate a destination and solidify its brand image. Whereas the 'hard,' more tangible factors such as infrastructure, accessibility, quality of facility, and financial incentives were clearly important in attracting sports groups, this study's findings confirmed that more nuanced factors also played a key role to that end. Notable in this regard were destinations recognized as being good host communities by offering exceptional services provided by DMO staff or trained volunteers.

Kaplanidou, Kerwin, and Karadakis (2013) propose that planning strategically for the future can help DMOs sustain the attractiveness of their destination. Feedback from most DMOs suggests that in past years opportunities in the sports market were seized as they emerged, rather than through using a formal strategic planning process (although a few of the larger destinations had sports commissions to help book and service an event). More recently, with the sports market established, DMOs have become more strategic in researching and pursuing various segments of the market. By understanding what has worked well in the past DMOs may be better able to plan strategically for the future.

In summarizing this discussion of findings, the following highlight what has worked well for DMOs' pursuit of the sports market as drawn from the four key groupings of dominant patterns and themes:

(1) Vigilant scanning for opportunities has and will continue to be a critical activity in DMOs. In addition to seeking new events for the same sports currently offered in their communities, DMOs should attempt to find new sports to add to their roster of events. As discussed earlier, many DMOs have broadened their scanning efforts to include opportunities offered by niche and emerging sports. The importance of adding such sports should increase when, as predicted by an evolving tourism life cycle, growth opportunities decline in what sports events a community currently hosts. Adding niche and emerging sports may also help communities make better use of facilities and help establish uniqueness as discussed below. DMOs became knowledgeable of opportunities by scanning across the range of sports events at trade shows and professional meetings. Such venues will continue to be important sources of information. The same holds true for information obtained in printed and, increasingly, from online sources. Some DMOs mentioned access through social media: a source that more DMOs are expected to use as a strategic way to market their destinations (Hays, Page, \& Buhalis, 2013). Scanning to identify new external individual and organizational contacts in the community will also increase the likelihood of finding opportunities in existing and new sports events.

(2) Efficient use of infrastructure will also figure prominently as communities seek to host more sports events. Whereas a few DMOs reported that their communities will develop new infrastructure for sports events, all DMOs said that their efforts have increasingly shifted toward maximum use of existing infrastructure, including infrastructure not created for sports events. In line with Ziakas and Costa (2011), the researchers see this trend in terms of communities building a portfolio of events that overcome the temporal limitations of single events. By multipurposing infrastructure, communities reduce the costs of building new infrastructure and avoid the pitfalls of overbuilding: a concern noted by some interviewees in light of what has happened with convention centers in some areas of the state. Thus, as the rate of growth in sports tourism declines in the future, the research team would anticipate seeing existing infrastructure used more innovatively to host a wider portfolio of events that span a longer time frame. 
(3) The findings of this study further suggest that all DMOs have found it necessary to build and maintain productive relationships with contacts and clients. This, too, will continue to be important to communities as growth in sports tourism eventually decelerates. DMOs will need to nurture extant relationships and attempt to build new relationships locally with sports leaders and citizens who may be influential in identifying and/or booking events. The same argument holds for maintaining existing client relationships, where DMOs have found that following up with clients, creating communication pathways through remote or face-to-face interaction, and building trust have helped to establish continuity in booking events.

Cooperative relationships with colleges and universities, as well as with other DMOs, have played an important role in the success of DMOs. Although occurring at a slower rate, interviewees felt that growth opportunities for sports tourism in the state will increase. With growth, some communities may face limited infrastructure for certain sports events. Under these conditions, cooperative relationships with colleges and universities may make new infrastructure available. Similarly, cooperative relationships among DMOs in the state creates a knowledge base for DMOs referring potential client sports groups to communities that can best accommodate their needs when the DMO has limited infrastructure or does not host the requested sports event.

(4) Although interviewees downplayed its significance, competition was acknowledged as a fact of life that was likely to increase in certain sports markets (usually the most popular sports events) as the rate of growth slowed down. Consistent with prior research studies (see Shonk \& Chelladurai, 2008), interviewees noted the importance of differentiating on the basis of service quality when competing head-to-head with other communities. Under these conditions, communities could be expected to further differentiate using service strategies mentioned in the interviews such as hosting special events for clients, using trained volunteers to assist event participants, and providing ample signage and free parking.

Many DMOs looked for ways to differentiate their sports events that minimized head-to-head competition whenever possible. For example, several communities have created imaginative new variants of traditional sports events, segmented demographically by age or athletic capability. Other DMOs avoided competing for the same events by taking advantage of unique manmade or natural infrastructure not available to other communities to host sports events that few others could offer. What has also helped to reduce competition is when a community has gained the status of being the place to host a type of sports event. These communities have often gained a first mover advantage by focusing their sports marketing efforts on this sport. We noted this in several communities that had developed unique infrastructure for water sports, cycling, and indoor track. When communities created a strong brand image for a sports event, DMOs in other communities tended to avoid competing with them.

As growth in the sports market continues to decline, competition to book events will increase among DMOs in the state. The competition, however, is unlikely to be as intense as DMOs competing to book events in convention centers, where overbuilding created excess capacity to serve a declining number of convention groups (Ford \& Peeper, 2007). This is because communities have avoided overbuilding and continue to find creative ways to maximize the use of existing infrastructure for sports events.

Given a preference to avoid competition, we envision DMOs focusing greater attention on new niche and emerging sports, even if it means breaking away from their traditional moorings. In an evolving market that seems to keep creating new opportunities, DMOs will continue to be on the lookout for a new type of sports event and then be first to market and try to hold the top perch for that event.

\subsection{Implications for theory and practice}

As the first study of its kind, the extant research has provided insight into how DMOs have taken advantage of the opportunities afforded by sports as a relatively new and rapidly growing segment of event tourism. Accordingly, it opens a new area for researchers to create and test theories that further our understanding of DMOs' pursuit of the sports event segment. As discussed above, the findings of this study follow prior research that highlights the key role of events in building and fortifying a destination's brand and reputation. More precisely, sports events create a central platform for branding initiatives (Rein \& Shields, 2007). Our findings also gain support from prior research suggesting that destinations require innovative approaches to compete in the sports market (Rein \& Shields, 2007). This was evident in how DMOs seized opportunities in emergent sports, multipurposed infrastructure, made use of natural and manmade facilities (Fenich, 2016), attempted to overcome the challenges of seasonality (Higham \& Hinch, 2001), and used contacts to identify and attract sports events (Gjertsen, 2017).

This research also has important implications for practice. By documenting how DMOs have identified, marketed, and serviced sports as an emergent growth opportunity for their communities, this study sheds light on specific ways in which DMOs might consider pursuing opportunities in the sports market. Specifically, DMO professionals could gain insight into making better decisions on which sports events would best fit in their communities. Importantly, they might become aware of hidden opportunities such as: using pre-existing manmade structures or the natural environment that could act as places for holding sports events; expanding the use of extant facilities to include a wider range of sports in more imaginative and competitive ways; identifying a range of sports events, including new sports, that they may not have been aware of; and seeking new local contacts to help bring in sports events.

Another implication of this research is that it addresses booking sports events as a way to mitigate some of the pressures confronting DMOs to book group business into a wide variety of lodging operations and to fill 'down' periods in a booking year. Moreover, with DMOs often criticized for not putting enough business into limited service properties and into non-downtown properties, booking sports events can help address another problem.

\subsection{Limitations and future research}

Given that this study focuses on one state, there are limitations to its generalizability. New studies across different regions and states can address this issue and reveal what differences may exist in how DMOs pursue sports tourism. By providing insight on the important issues that DMOs consider in pursuing the sports tourism market, the results of this study create new opportunities for researchers. In addition to interviews, researchers can use surveys to obtain information in focused areas. Examples could include the following:

- Are there regional differences in how DMOs approach sports tourism and the likely reasons why such differences might exist?

- The process of creating a unique brand for specific sports events.

- How DMOs build relationships with outside groups such as DMOs in other communities, local citizens and organizations that help in securing bookings for sports events, local colleges and universities, and contacts in professional organizations and sports groups.

- The role of the internet, including social media, in identifying and marketing sports group targets.

- Categorizing different innovative approaches taken by DMOs to make the most of infrastructure and how they have contributed to the community's experience in hosting sports events.

- How communities perceive the potential threat of a mature market in sports tourism and what steps they are likely to take.

- To what extent can DMOs influence the construction of new sports 
infrastructure?

- Determining the impact of sports events in creating/developing tourism

\section{Appendix A. Questions that served as an interview protocol}

1. What sports segments do you see emerging for DMOs?

2. How is your DMO pursuing these segments?

3. How has your DMO reconfigured itself to pursue these segments?

4. How has your DMO reworked its budgets to pursue these segments?

5 . Where is all this headed? What trends are emerging?

6. What are the key elements that destinations must be able to offer to pursue these segments?

7. Which segments are the most profitable for you as a destination?

8. Are there some segments that work better in smaller versus larger cities?

9. What are the keys things that you have learned so far in pursuing these segments?

10. Have you experienced competition for sports business from colleges and universities?

11. Did sports groups book more full or limited service rooms?

\section{Appendix B. Destination marketing organizations interviewed in} the study

- Convention Visitors Bureau, Asheville, North Carolina

- Convention Visitors Bureau, Charlotte, North Carolina

- Convention Visitors Bureau, Concord/Cabarrus County, North Carolina

- Convention Visitors Bureau, Durham, North Carolina

- Department of Travel and Tourism, Gaston County, North Carolina

- Convention Visitors Bureau, Greensboro, North Carolina

- Convention Visitors Bureau, Greenville, North Carolina

- Convention Visitors Bureau, Hickory, North Carolina

- Convention Visitors Bureau, Salisbury/Rowan County, North Carolina

- Convention Visitors Bureau, Winston-Salem, North Carolina

\section{References}

Alexandris, K., \& Kaplanidou, K. (2014). Marketing sport event tourism: Sport tourist behaviors and destination provisions, Sport Marketing Quarterly, 23(3), 125-127.

Bawaba, A. (2010). African appreciation for Tunisian experience in the areas of women and youth. Tunis Afrique Presse23 (January 23).

Bob, U., \& Swart, K. (2010). Sport events and social legacies. Alternation, 17(2), 72-95. Bogner, A., \& Menz, W. (2009). The theory-generating expert interview: Epistemological interest, forms of knowledge, interaction. In A. Bogner, B. Littig, \& W. Menz (Eds.). Interviewing experts (pp. 43-80). London: Palgrave Macmillan.

Ciampicacigli, R., \& Maresca, S. (2004). The metalanguages between sport and tourism. Symphonya Emerging Issues in Management, 2, 73-80.

Cooper, C., \& Jackson, S. (1989). Destination life cycle: The isle of man case study. Annal of Tourism Research, 16(3), 377-398.

Cornelissen, S., Bob, U., \& Swart, K. (2011). Development Southern Africa, 28(3), 305306.

Creswell, J. W. (2013). Qualitative inquiry and research design: Choosing among five approaches (3rd ed.). Los Angeles, CA: Sage.

Desai, A., \& Vahed, G. (2010). World Cup 2010: Africa's turn or the turn on Africa? Soccer \& Society, 11(1-2), 154-167.

Destination Marketing Association International (2016). About the industry. Retrieved from 〈http://Www.destinationmarketing.org/topics/about-industry〉.

Emery, P. R. (2002). Bidding to host a major sports event: The local organising committee perspective. International Journal of Public Sector Management, 15(4), 316-335.

Fenich, G. G. (2016). Meetings, expositions, events, and conventions: An introduction to the industry (4th ed.). London: Pearson.

Ford, R. C., \& Peeper, W. C. (2007). The past as prologue: Predicting the future of the convention and visitor bureau industry on the basis of its history. Tourism Management, 28(4), 1104-1114.

Gaffney, C. (2010). Mega-events and socio-spatial dynamics in Rio de Janeiro, 19192016. Journal of Latin American Geography, 9(1), 7-29.

Getz, D. (2008). Event tourism: Definition, evolution, and research. Tourism Management, 29(3), 403-428.

Getz, D., \& Page, S. J. (2016). Progress and prospects for event tourism research. Tourism Management, 52, 593-631.

Gillham, B. (2005). Research interviewing: The range of techniques. Maidenhead: Open University Press.

Gjertsen, T. (May 2017). The North Cape Walk-from amateur to professional sport tourism? STC'16, Sport Tourism Conference Proceedings, University of Zagreb, Faculty of Business and Economics, Zagreb, pp. 92-121.

Gratton, C., Dobson, N., \& Shibli, S. (2000). The economic importance of major sports events: A case-study of six events. Managing Leisure, 5(1), 17-28.

Hays, S., Page, S. J., \& Buhalis, D. (2013). Social media as a destination marketing tool: Its use by national tourism organisations. Current issues in Tourism, 16(3), 211-239.

Higham, J. (1999). Commentary-sport as an avenue of tourism development: An analysis of the positive and negative impacts of sports tourism. Current Issues in Tourism, 2(1), $82-90$.

Hinch, T. D., \& Higham, J. E. S. (2001). Sport tourism: A framework for research. The International Journal of Tourism Research, 3(1), 45-58.

Hinch, T. D., \& Higham, J. E. (2004). Sport tourism development. Clevedon: Channel View Publication.

Kaplanidou, K., \& Gibson, H. J. (2010). Predicting behavioral intentions of active event sport tourists: The case of a small-scale recurring sports event. Journal of Sport $\mathcal{E}$ Tourism, 15(2), 163-179.

Kaplanidou, K., Kerwin, S., \& Karadakis, K. (2013). Understanding sport event success: Exploring perceptions of sport event consumers and event providers. Journal of Sport E Tourism, 18(3), 137-159.

Knott, B., \& Hemmonsbey, J. D. (2015). The strategic value of sport for an African city brand. African Journal for Physical Health Education, Recreation and Dance, 21(Supplement 2), 191-204.

McCracken, G. (1988). The long interview. Newbury Park, CA: Sage.

Morgan, N., Pritchard, A., \& Pride, R. (2011). Destination brands: Managing place reputation. London: Routledge.

Munro, J., \& Richards, B. (2011). The digital challenge. In N. Morgan, A. Pritchard, \& R. Pride (Eds.). Destination brands: Managing place reputation (pp. 141-154). London: Routledge.

Nyikana, S., Tichaawa, T. M., \& Swart, K. (2014). Sport, tourism and mega-event impacts on host cities: A case study of the 2010 FIFA World Cup in Port Elizabeth: Tourism. African Journal for Physical Health Education, Recreation and Dance, 20(21), 548-556.

Pike, S., \& Page, S. J. (2008). Destination marketing organizations and destination marketing: A narrative analysis of the literature. Tourism Management, 40(1), 202-227.

Pittman, J., \& McLaughlin, B. (2012). Professional conferences, social capital and tourism: Is the alliance in jeopardy? Journal of Tourism \& Hospitality, 1(2), 1-3.

Rein, I., \& Shields, B. (2007). Place branding sports: Strategies for differentiating emerging, transitional, negatively viewed and newly industrialised nations. Place Branding and Public Diplomacy, 3(1), 73-85.

Russo, B., \& Zarick, J. (2010). The trends in dining, lodging, entertainment, and recreation among Virginia youth travel soccer participants, their family, and friends when traveling for youth travel soccer tournaments. Journal of Tourism Insights, 1(1), 91-97.

Shonk, D. J., \& Chelladurai, P. (2008). Service quality, satisfaction and intent to return in event sport tourism. Journal of Sport Management, 22(5), 587-602.

Siyabulela, N. (2016). Using sport tourism events as a catalyst for tourism development in the Eastern Cape Province, South Africa. African Journal of Hospitality, Tourism and Leisure, 5(3), 1-10 (open access).

Smith, A. (2014). Leveraging sport mega-events: New model or convenient justification? Journal of Policy Research in Tourism, Leisure and Events, 6(1), 15-30.

Standeven, J., \& De Knop, P. (1999). Sport tourism. Champaign, IL: Human Kinetics.

Swart, K., \& Bob, U. (2007). The eluding link: Toward developing a national sport tourism strategy in South Africa beyond 2010. Politikon, 34(3), 373-391.

Tichaawa, T. M., \& Swart, K. (2010). South Africa's image amongst African fans and factors that will influence their participation in the 2010 FIFA World Cup: The case of Cameroon. In Proceedings of UNWTO/South Africa International Summit on Tourism, Sport and Mega-events, 24 February, Johannesburg.

Ziakas, V., \& Costa, C. A. (2011). Event portfolio and multi-purpose development: Establishing the conceptual grounds. Sport Management Review, 14(4), 409-423. 